\title{
The Life Cycle Assessment Of The Coal, Oil, And LNG
}

\author{
Hui Jiang ${ }^{1,}$, Yun Zhang ${ }^{1, b,},{ }^{*}, Y u Q^{1, c}$, Yufei Zeng ${ }^{1, d}$ \\ ${ }^{1}$ Key Laboratory of Industrial Ecology and Environmental Engineering (MOE), \\ School of Environmental Science and Technology, Dalian University of Technology, \\ Linggong Road 2, Dalian 116024, China \\ ajianghui4928@163.com, ${ }^{\mathrm{b}}$ zhangyun@dlut.edu.cn, ${ }^{\mathrm{c}}$ qiyudlut@126.com, ${ }^{\mathrm{d}}$ zengyufei@163.com \\ *Correspondence to: Yun Zhang; Tel.: +86 411 84706151; E-mail address: zhangyun@dlut.edu.cn
}

Keywords: Life cycle assessment; LNG; Coal; Oil

Abstract.Coal is used as the basic energy source in China, however, the exploitation and utilization of coal has a serious environmental impact. Compared to coal and petroleum, the LNG has less storage space, easy transportation and storage, large calorific value, and higher safety performance. Therefore, we build the life cycle inventory from the exploitation stage to usage stages. We choose four environmental impact categories include GWP, AP, EP, and POCP as the environmental impact assessment indicators. Through the life cycle assessment (LCA) we can analyze the environmental impact of the coal, oil and LNG.

\section{Introduction}

Energy is indispensable basis for the social progress, human survival and development. The coal consumption accounted for $68.8 \%$ of the total primary energy consumption in China. However, the coal consumption accounted for the proportion of energy consumption is less than 30\%[1]。 The combustion of fossil fuels, especially the coal, is one of the largest sources of pollutions. Compared to coal and petroleum, the usage of natural gas is more efficient. LNG is natural gas that is cooled to $-162^{\circ} \mathrm{C}$ to coagulate it[2]. LNG has less storage space, easy transportation and storage, large calorific value, and higher safety performance[3].

Although LNG is clean energy, $\mathrm{CO}_{2}$, $\mathrm{NOx}$, and $\mathrm{CH}_{4}$ discharged into the atmosphere will cause harm to the environment and human. Therefore, this article evaluates the environmental impact of the coal, oil and LNG through life cycle assessment from exploitation, treatment, transportation to combustion stage. This article adopts the method of life cycle assessment (LCA) to evaluate three kinds of energy using Gabi software. LCA is an analytical method for the direct and indirect environmental impact in the entire life cycle.

\section{Methodology}

In 1990, the environmental toxicology and chemical society defined life cycle assessment (LCA): Life cycle assessment is an objective process to evaluate the environmental pressure of a product, process, and activity. In 1997, the ISO14040 standard divided the life cycle assessment into four parts: the determination of the purpose and scope, inventory analysis, impact assessment and result interpretation.

The functional unit is $1000 \mathrm{t}$ coal, oil and LNG, and transport distance is $1 \mathrm{~km}$. The LCA system boundary of coal includes exploitation, transportation and combustion stages, and the exploitation stage includes exploitation, washing and conveyor. The LCA system boundary of oil includes exploitation, transportation and combustion stages, and the exploitation stage includes oil extraction and gas gathering. The LCA system boundary of LNG includes exploitation, gasification, transportation and combustion stages[4], and the exploitation stage includes exploitation, pretreatment and liquidation.

The inventory quantifies and analyzes the energy consumption and pollution emissions of the 
product, process and activity in their entire life cycle. The inventory of this article includes imported and exported data, and carries it on to the discussion, verification and analysis. Data mainly comes from the statistical yearbook both at home and abroad, environmental impact statements and enterprise actual operation data and so on. The inventory of the coal, oil and LNG is shown in Table 1[5].

Table 1 The inventory of the coal, oil and LNG

\begin{tabular}{cccccc}
\hline & name & unit & Coal & Oil & LNG \\
\hline \multirow{4}{*}{ input } & electricity & $\mathrm{kWh}$ & 27740 & 83440 & 240634.01 \\
& water & $\mathrm{t}$ & 1670 & 2099.8 & 75395.51 \\
& coal & $\mathrm{t}$ & 277.4 & $/$ & $/$ \\
& oil & $\mathrm{kg}$ & $/$ & 3066 & $/$ \\
& natural gas & $\mathrm{t}$ & $/$ & $/$ & 8.68 \\
& gasoline & $\mathrm{kg}$ & $/$ & 85050 & $/$ \\
& diesel & $\mathrm{kg}$ & 2.5 & 56810 & $/$ \\
\hline \multirow{5}{*}{ output } & $\mathrm{CO} 2$ & $\mathrm{t}$ & 1784.3 & 60.6 & 2421.29 \\
& $\mathrm{CO}$ & $\mathrm{t}$ & 2.42 & 1.25 & 0.18 \\
& $\mathrm{NO}_{\mathrm{x}}$ & $\mathrm{t}$ & 11.17 & 1.25 & 0.6 \\
& $\mathrm{CH}_{4}$ & $\mathrm{t}$ & 4.47 & $/$ & 11.14 \\
& $\mathrm{NMVOC}$ & $\mathrm{kg}$ & 719 & $/$ & $/$ \\
& $\mathrm{SO}_{2}$ & $\mathrm{t}$ & 17.51 & 2.48 & 0.07 \\
\hline
\end{tabular}

According to the actual situation, this article selects the environmental impact categories as GWP, $\mathrm{AP}, \mathrm{EP}$ and POCP.

The result explanation is based on the results of the inventory analysis and impact assessment to identify the major issues of the product life cycle and to evaluate the results, including integrity, sensitivity and consistency[6].

\section{Results and discussion}

Because the environmental impact potential is different with three kinds of energy, we calculate environmental impact through Gabi 5 software. The environmental impact categories are GWP, AP, EP and POCP. The analysis results of three kinds of energy are shown in Fig. 1.
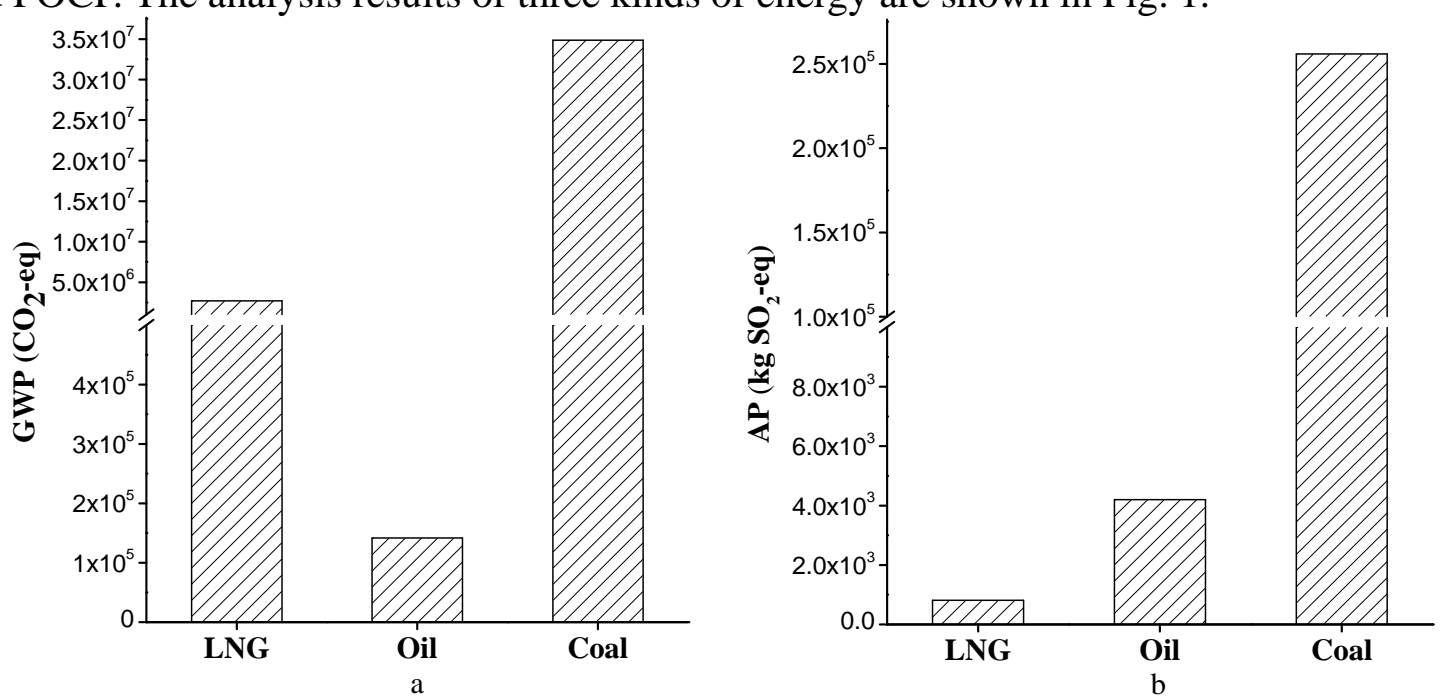

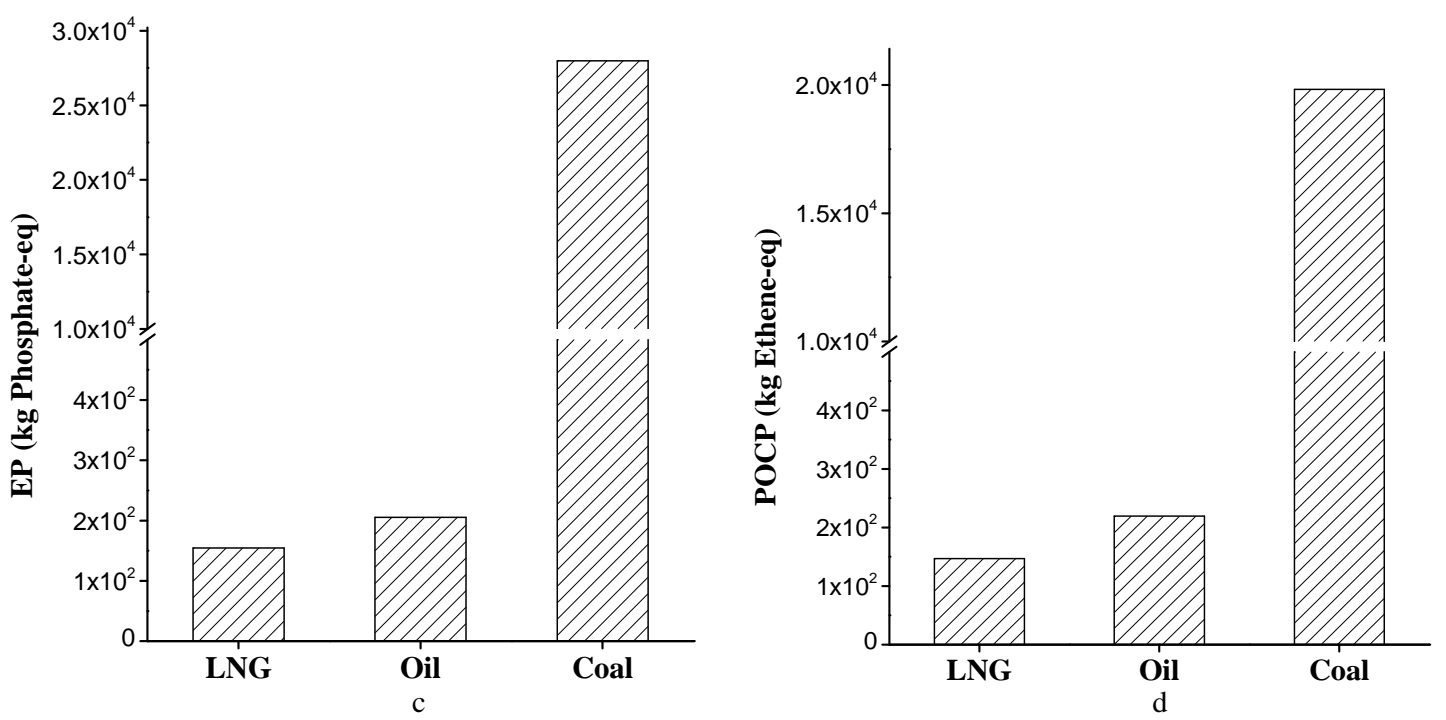

Fig. 1 The environmental impact potential of the coal, oil and LNG

GWP is mainly due to $\mathrm{CO}_{2}$ emissions; secondly, $\mathrm{CH}_{4}$ and $\mathrm{CO}$ also play a small role. As shown in figure 3.1 (a), the largest contribution of GWP is the coal and LNG, and the smallest contribution is the oil.

AP is mainly due to the emissions of $\mathrm{NO}_{x}$ and $\mathrm{SO}_{2}$. As LNG is pre-processed, it is a clean energy, the contribution of $\mathrm{SO}_{2}$ is less than $\mathrm{NO}_{\mathrm{x}}$ for AP. As shown in figure 3.1 (b), the AP of LNG is much higher than the coal and oil.

$\mathrm{EP}$ is usually caused by excess $\mathrm{N}$ and $\mathrm{P}$ element content in water, and the impact of $\mathrm{N}$ is highest in the LNG life cycle. This article uses $\mathrm{NO}_{3}{ }^{-}$as a reference to determine equivalent coefficient. As shown in figure 3.1 (c), the largest contribution of GWP is the coal, and the smaller contribution is the oil and LNG.

The contribution of POCP is mainly highest, and ethylene is the reference. As shown in figure 3.1 (d), the largest contribution of GWP is the coal, and the smaller contribution is the oil and LNG.

This article selects the range of error as plus or minus $1 \%$, namely when a certain factor changes $1 \%$, this factor after calculating changes value. The higher the value is, the larger the impact on final results, so that we can determine the factor which is causing the highest environmental impact. Specific results are shown in Table 2.

Table 2 The sensitive value of the coal, oil and LNG

\begin{tabular}{cccc}
\hline & LNG & Oil & Coal \\
\hline GWP & Carbon dioxide & Carbon_dioxide & Electricity \\
AP & Electricity & Sulphur dioxide & Electricity \\
EP & Nitrogen dioxid & Nitrogen dioxid & Electricity \\
POCP & Electricity & Sulphur dioxide & Electricity \\
\hline
\end{tabular}

For the LNG, the highest impact factors for GWP and EP is $\mathrm{CO}_{2}$ and NOx emissions respectively. However, the highest impact factors for AP and POCP is electricity. For the oil, the highest impact factors for GWP and EP is $\mathrm{CO}_{2}$ and NOx emissions respectively. However, the highest impact factors for AP and POCP is electricity. For the coal, the highest impact factors for GWP, AP, EP and POCP is electricity.

\section{Conclusions}

This article constructs the coal, oil and LNG life cycle inventory including imported materials, energy and exported pollutants This article selects GWP, AP, EP and POCP as indicators of environmental impact assessment. This article concludes with the specific results as follows: 
(1) The largest environmental impact of the coal, oil and LNG for the GWP, AP, EP and POCP is the coal. With the exception of GWP, the smallest environmental impact for other categories is LNG. Therefore, we can make LNG substitute the coal so that it can reduce the environmental impact.

(2) Through the sensitivity analysis, we can know the largest contribution on the coal is the electricity. For the oil and LNG, except for the impact of the electricity, we can know that $\mathrm{CO}_{2}$, $\mathrm{NOx}$, and $\mathrm{SO}_{2}$ make a certain impact.

\section{Acknowledgements}

This study was supported by the Major Science and Technology Program for Water Pollution Control and Treatment (2012ZX07202-001).

\section{References}

[1] Fengling Yu (2014). The empirical study on the relationship between energy and economic development in China. Changsha: Central South University.(In Chinese)

[2] Cun Xiang (2007). Alternative energy sources and the development of LNG industry in China. Sun Yatsen University Forum, 27(2): 78-82. (In Chinese)

[3] Keming Han (2014). The Feasibility Study for the LNG Project of JiLin JiYuan Compan. Changchun: Jilin University. (In Chinese)

[4] Singh, B., Strømman, A.H., Hertwich, E. (2011) Life cycle assessment of natural gas combined cycle power plant with post-combustion carbon capture, transport and storage. International Journal Of Greenhouse Gas Control 5: 457-466.

[5] Agrawal, K.K., Jain, S., Jain, A.K. et al. (2014) A life cycle environmental impact assessment of natural gas combined cycle thermal power plant in Andhra Pradesh, India. Environmental Development 162-174.

[6] ISO: International Organization for Standardization, Life Cycle Assessment - Requirements and Guidelines, ISO 14040. 